\title{
Effect of Different Cooking Methods on Vitamin C Content of Some Selected Vegetables
}

\author{
Mst. Rita Khatun, Mst. Khodeza Khatun, Md. Shadiqul Islam, Sharif Md. Al-Reza* \\ Department of Applied Chemistry and Chemical Engineering, Islamic University, \\ Kushtia-7003, Bangladesh \\ *Corresponding author
}

\section{A B S T R A C T}

\begin{tabular}{|l|}
\hline Ke y w o r d s \\
Nutrition, Vitamin \\
C, Fresh \\
Vegetables, Cooked \\
vegetables, Redox \\
titration
\end{tabular}

\section{Introduction}

Vegetables and fruits are valuable components of the daily diet contributing carbohydrate in form of dietary fibre, vitamins and minerals to the body (Babalola et al., 2010). Most vegetables are commonly cooked before consumption. In general, vegetables are cooked at home on the basis of convenience and taste preference of consumer rather than retention of nutrient and health promoting compounds (Singh and Harshal, 2016). The degree of vitamin loss is influenced by various factors including: type of food, variety of vegetables, method of cutting, duration and processing of cooking (Rumm-Kreuter and
Demmel, 1990). Vitamin C (Ascorbic acid) was first isolated in 1928 by the Hungarian biochemist and Nobel Prize winner SzentGyorgyi. Vitamin $\mathrm{C}$ is available in reduced form (L-ascorbic acid) and oxidized form (Ldehydro ascorbic acid).

It is a water soluble vitamin and sensitive to heat and oxygen, therefore leaching into the cooking water may occur during processing resulting in the potential loss during industrial processing or domestic cooking. In addition, leaves of the vegetables may absorb a large amount of cooking water and this can lead to dilution and further reduction in the level of vitamins in the cooked product (Prabhu and Barrett, 2009). 
Great interest has been seen in the clinical roles of Vitamin $C$ because of evidence that oxidative damage is a root cause and mostly associated with many diseases. Population studies have shown that individuals with high intakes of Vitamin $\mathrm{C}$ have lower risk of chronic diseases including, heart disease, cancer, eye diseases and neurodegenerative conditions (Jacob and Sotoudeh, 2002). Diet supplies more than $90 \%$ of the Vitamin C in human by fruits and vegetables (Kumar et al, 2013). Except human and other primates, most of the higher animals can synthesize Vitamin C (L-ascorbate). Humans lack the enzyme (Lgluconolactone oxidase, GLO) which is needed to convert glucose to Vitamin C (Cheema and Pant, 2011). It is therefore important to include plenty of Vitamin C containing foods in daily diet.

Vitamin $C$ plays significant functions in the body. The biochemical functions of Vitamin $\mathrm{C}$ includes: Stimulation of certain enzymes, collagen biosynthesis, hormonal activation, antioxidant, detoxification of histamine, phagocytic functions of leukocytes, formation of nitrosamine and proline hydroxylation amongst others.

Vitamin $\mathrm{C}$ has been associated with reduction of incidence of cancer, blood pressure, immunity and drug metabolism and urinary hydroxyproline excretion, tissue regeneration (Walingo, 2005). Study published in Anticancer Research in 1992 reported that use of high-dose antioxidants in conjunction with chemotherapy and radiation prolonged survival in patients with small-cell lung cancer (Lawson, 2005).

The recommended dietary allowance (RDA) for Vitamin $\mathrm{C}$ for non smoking adult male and female was $60 \mathrm{mg} /$ day (Jacob and Sotoudeh, 2002). The new higher Recommended Dietary Allowance (RDA) for Vitamin C is $75 \mathrm{mg}$ for women and $90 \mathrm{mg}$ for men because it acts as an antioxidant as well as for protection from deficiency (Carr and Frei, 1999). Since smokers suffer increased oxidative stress there recommended dietary allowance is increased by $35 \mathrm{mg} /$ day.

Studies from the UK and North America have reported Vitamin $\mathrm{C}$ deficiency in around 1 in 5 men and 1 in 9 women in low income groups (Ravindran et al., 2011). The prevalence of Vitamin C deficiency is highest among Indians and people of South Asian origin compared to other races except the Mexican population.

Lower intake of fresh fruits and vegetables and over-cooking of food by South Asians might be the reason for higher prevalence of Vitamin $\mathrm{C}$ deficiency in these populations. Also this deficiency of Vitamin $\mathrm{C}$ may be the one of the reason for higher rates of cardiovascular disease and cancer among South Asians individuals in Pakistani, Indian, Malay and Chinese populations compared to most Western populations (Khan and Iqbal, 2006). Deficiency was more prevalent in men with increasing age, users of tobacco and biomass fuels with poor nutrition and with lower intakes of dietary Vitamin C (Ravindran et al., 2011).

The redox titration method was used for the determination of vitamin $\mathrm{C}\left(\mathrm{C}_{6} \mathrm{H}_{8} \mathrm{O}_{6}\right)$ in this research. As the iodine is added during the titration, the ascorbic acid is oxidized to dehydroascorbic acid, while the iodine is reduced to iodide ions.

$\mathrm{C}_{6} \mathrm{H}_{8} \mathrm{O}_{6}+\mathrm{I}_{2} \rightarrow 2 \mathrm{I}^{-}+\mathrm{C}_{6} \mathrm{H}_{6} \mathrm{O}_{6}$

The purpose of this work is to determine the effect of different cooking methods on the vitamin $\mathrm{C}$ of the selected vegetables. The values obtained in the cooked samples were compared with the data found in fresh vegetables. 


\section{Material and Methods}

\section{Sample Collection}

Eight vegetables commonly consumed in Bangladesh were purchased from the local market, Kushtia City. The vegetable samples are Potato (Solanum tuberosum), Spinach (Spinacia oleracea), Cauliflower (Brassica oleracea var. botrytis), Onion (Allium cepa), Chili (Capsicum annum), Broccoli (Brassica oleracea var. italica), Brinjal (Solanum melongena) and Cabbage (Brassica oleracea var. capitata f. alba). All the apparatus used were properly washed and rinsed with distilled water. Reagents (analytical grade) for the experiment were obtained from commercial sources (Sigma-Aldrich, St. Louis, MO, USA).

\section{Preparation of Reagents}

\section{1\% Starch Indicator Solution}

A starch solution (1\%) was prepared by weighing $1 \mathrm{~g}$ of starch into a $250 \mathrm{ml}$ beaker and $100 \mathrm{ml}$ of distilled water was added. The mixture was boiled for 5 minutes with stirring until the starch dissolved; the resulting solution was allowed to cool.

\section{Potassium iodide solution}

To prepare $0.005 \mathrm{M}$ of iodine solution $2 \mathrm{~g}$ of KI was taken in a $500 \mathrm{ml}$ beaker and dissolved in $100 \mathrm{ml}$ distilled water and $1.3 \mathrm{~g}$ of iodine powder was stirred with small quantity of water until dissolved and transfer iodine solution to a $1 \mathrm{~L}$ volumetric flask, making sure to rinse all traces of solution into the volumetric flask with distilled water until the volume up to the mark.

\section{Sample Preparation}

The fresh vegetable samples were collected and immediately washed with distilled water to remove adhering dirty particles. All the vegetables were fried by traditional frying method in vegetable oil until brown on the outside and tender, almost velvety on the inside. They were boiled with water for 10 minutes and steaming for 10-15 minutes at boiling point of water. $100 \mathrm{~g}$ of each sample (fresh, fried, boiled and steamed) was weighed and blended with $100 \mathrm{ml}$ of water using an electric blender. The mixture was filtered, the filtrate was collected in a $200 \mathrm{ml}$ volumetric flask and diluted up to the mark with distilled water for each sample.

\section{Experimentals}

$10 \mathrm{ml}$ of the sample solution was pipetted out into $250 \mathrm{ml}$ conical flask and then added 4drops of starch indicator solution. $0.005 \mathrm{M}$ iodine solution was filled into the burette and titrated against the sample in the beaker until the first permanent trace of dark blue-black colour observed due to the starch iodine complex. The procedure was done in triplicate and the average titration value for each sample was obtained. Then using the burette reading vitamin $\mathrm{C}$ concentration was determined by using the following formula:

$1 \mathrm{ml} 1 \mathrm{M} \mathrm{I}_{2}$ solution $\equiv 0.17613 \mathrm{gm}$ of ascorbic acid

The percentage lost on the ascorbic acid due to cook heating was calculated using the formula: $\%$ loss $=\frac{\text { AAF }- \text { AAC }}{\text { AAF }}$

Where, $\mathrm{AAF}=$ the ascorbic acid content in the fresh sample

AAC $=$ the ascorbic acid content of the cooked sample

\section{Results and Discussion}

The present report here the vitamin $\mathrm{C}$ content of fresh, fried, boiled and steamed samples of eight vegetables purchased from local market. 
The retention of vitamin $\mathrm{C}$ is often used as estimation for overall nutrient retention of food products because it is highly sensitive to oxidation and leaching into water during cooking.

The effects of cooked showed that the vitamin C content were different from fresh sample than the other cooked samples. It has also been reported (Bello and Fowoyo, 2014) that the higher temperature, greater the loss of vitamin $\mathrm{C}$ in fruits and vegetables has to be. Adefegha and Oboh also attributed that the loss of vitamin $\mathrm{C}$ content during the different cooking processes could be due to the fact that vitamin $\mathrm{C}$ is highly soluble in water and is very unstable at high temperatures (Adefegha and Oboh, 2011).

The vitamin $\mathrm{C}$ content of the raw vegetables is generally high when compared with those of the heated. It was also observed that heating affected the vitamin $\mathrm{C}$ content of all the vegetables, as the heating time increases, the vitamin C content decreases, while the temperature was kept constant (Igwemmar et al., 2013). Loss as a result of frying, boiling and steaming can be justified since vitamin $\mathrm{C}$ is water soluble and heat labile. The vitamin $\mathrm{C}$ concentration in $\mathrm{mg} / 100 \mathrm{~g}$ sample of the vegetables as affected by different cooking methods is shown on Table 1 .

The results revealed that among all the fresh vegetables chili gave the highest value of $241.30 \mathrm{mg} / 100 \mathrm{~g}$ implying it is a good source of vitamin $\mathrm{C}$ while brinjal gave the least of $2.64 \mathrm{mg} / 100 \mathrm{~g}$. The vitamin $\mathrm{C}$ content of the raw vegetables is generally high when compared with those of the cooked vegetables. It was also observed that heating affected the vitamin $\mathrm{C}$ content of all the vegetables, as the heating time increases, the vitamin $\mathrm{C}$ content decreases (Lee et al., 2018). The losses observed in this study are high most especially when the vegetables were subjected to frying and boiling as comparing to steaming (Table $1)$.

Table.1 Comparative result of vitamin C content of fresh vegetables with other cooked samples

\begin{tabular}{|l|l|l|l|l|}
\hline \multirow{2}{*}{ Vegetables } & Fresh & Fried & Boiled & Steamed \\
\cline { 2 - 5 } & \multicolumn{3}{|c|}{ Content of vitamin C (mg/100g) } \\
\hline Potato & $18.20 \pm 1.5$ & $5.90 \pm 0.1$ & $12.86 \pm 1.2$ & $15.24 \pm 1.1$ \\
\hline Spinach & $88.33 \pm 1.0$ & $15.24 \pm 1.5$ & $44.30 \pm 1.0$ & $79.87 \pm 0.6$ \\
\hline Cauliflower & $55.48 \pm 0.5$ & $36.99 \pm 1.0$ & $26.68 \pm 1.2$ & $45.79 \pm 1.2$ \\
\hline Onion & $4.67 \pm 1.2$ & $1.76 \pm 1.1$ & $2.38 \pm 0.5$ & $3.52 \pm 1.0$ \\
\hline Chili & $241.30 \pm 1.5$ & $9.68 \pm 0.5$ & $16.12 \pm 1.5$ & $17.88 \pm 1.5$ \\
\hline Broccoli & $79.26 \pm 0.5$ & $35.23 \pm 1.0$ & $44.03 \pm 1.1$ & $61.03 \pm 1.2$ \\
\hline Brinjal & $2.64 \pm 1.2$ & $1.76 \pm 1.0$ & $1.76 \pm 1.1$ & $2.38 \pm 1.0$ \\
\hline Cabbage & $48.44 \pm 1.1$ & $18.23 \pm 1.2$ & $45.18 \pm 1.2$ & $45.79 \pm 0.5$ \\
\hline
\end{tabular}

Values are given as mean \pm S.D. $(n=3)$

The study done clearly highlights that vitamin $\mathrm{C}$ activity drops on treatment with heat. The percentage of vitamin C activity loss was 33-95\% on frying, 6-93\% on boiling and 5-92\% on steaming (Figure 1). 


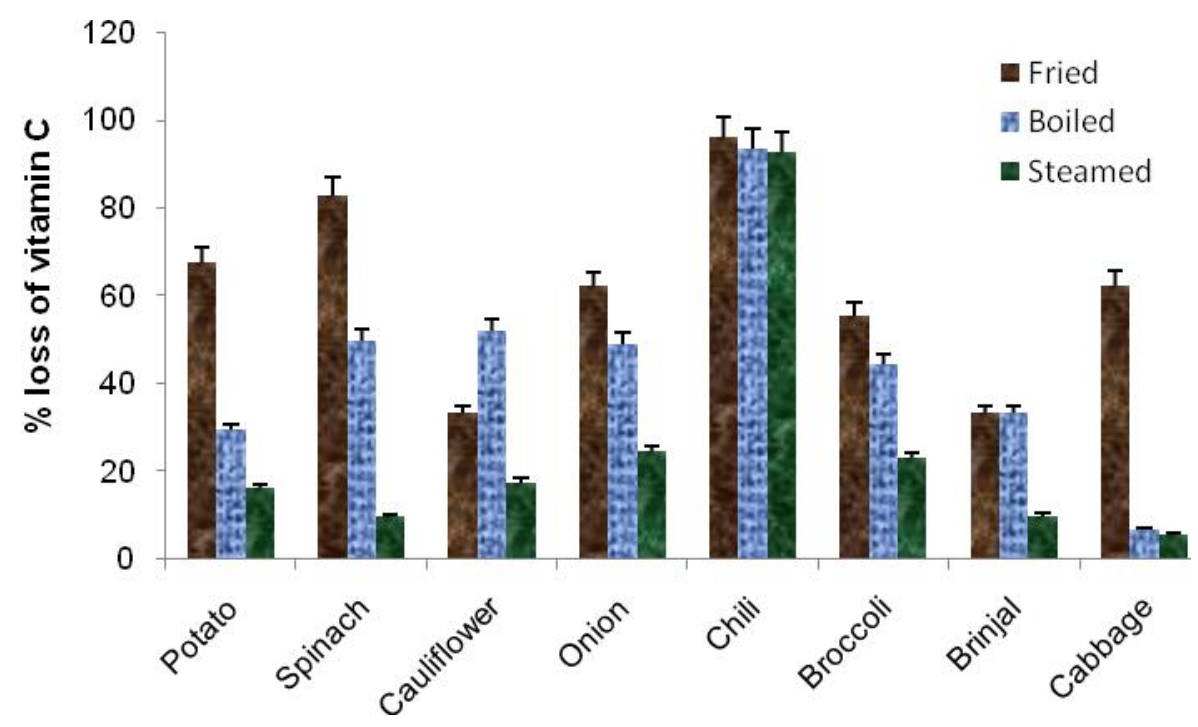

Fig. 1 Percentage reduction of vitamin $\mathrm{C}$ after subjecting to various cooking methods

Vitamin $\mathrm{C}$ is the very unstable vitamin which can easily be denatured. Of all the vegetables, chili gave the highest level of vitamin $\mathrm{C}$ $(241.30 \mathrm{mg} / 100 \mathrm{~g})$ and also a $95.99 \%$ loss of vitamin $\mathrm{C}$ after frying. This suggests that denaturation of vitamin $\mathrm{C}$ due to heating depends on its availability in the vegetable. Thus water soluble vitamin $\mathrm{C}$ leaches into cooking water and gets degraded. This study suggests that we should consume vegetables in fresh form as to get maximum nutrition with regard of ascorbic acid (vitamin C) especially. Also appropriate cooking methods which cause minimum destruction of vitamin $\mathrm{C}$ and other nutrients in food should be followed to overcome the vitamin $\mathrm{C}$ deficiency prevailing in our daily life.

\section{References}

Adefegha, S.A., Oboh, G., 2011. Cooking enhances the antioxidant properties of some tropical green leafy vegetables. Afr. J. Biotech. 10(4):632-39.

Babalola, O.O., Tugbobo O.S., Daramola A.S., 2010. Effect of processing on the vitamin C content of seven Nigerian green leafy vegetables. Adv. J. Food Sci. Tech. 2(6): 303-305.
Bello, A.A., Fowoyo, P.T., 2014. Effect of heat on the ascorbic acid content of dark green leafy vegetables and citrus fruits. Afr. J. Food Sci. Technol. 5(4):114-118.

Carr, A.C., Frei, B., 1999. Toward a new recommended dietary allowance for vitamin $\mathrm{C}$ based on antioxidant and health effects in humans. The American J. clinical nutri. 69(6):1086-1107.

Cheema, S.K., Pant, M.R., 2011. Estimation of Vitamin C in seven cultivated varieties of Capsicum annuum L. Int. J. Ph. Sci. 3:1397-1401.

Igwemmar, N.C., Kolawole, S.A., Imran, I.A., 2013. Effect of heating on vitamin C content of some selected vegetables. Int. J. Sci. Tech. Res., 2(11):209-212.

Jacob, R.A., Sotoudeh, G., 2002. Vitamin C function and status in chronic disease. Nutr. Clin. Care. 5(2):66-74.

Khan, R.M., Iqbal, M.P., 2006. Deficiency of vitamin $\mathrm{C}$ in South Asia. Pakistan $J$. Med. Sci. 22(3):347.

Kumar, G.V., Ajay Kumar, K., Raghu, P.G., Manjappa, S., 2013. Determination of vitamin $\mathrm{C}$ in some fruits and vegetables in Davanagere city, (Karanataka)-India. Int. Pharma. Life Sci. 4(3):2489-2491.

Lawson, S., 2005.Recent Research on 
Vitamins $\mathrm{C}$ and $\mathrm{E}$.

Lee, S., Choi,, Y., Jeong, H.S., Lee, J., Sung, J., 2018. Effect of different cooking methods on the content of vitamins and true retention in selected vegetables. Food sci. biotech. 27(2): 333-342.

Prabhu, S., Barrett, D.M., 2009. Effects of storage condition and domestic cooking on the quality and nutrient content of African leafy vegetables (Cassia tora and Corchorus tridens). J. Sci. Food Agric. 89(10):1709-1721.

Ravindran, R.D., Vashist, P., Gupta, S.K., Young, I.S., Maraini, G., Camparini, M., Jayanthi, R., John, N., Fitzpatrick, K.E., Chakravarthy, U., Ravilla, T.D. 2011. Prevalence and risk factors for vitamin C deficiency in north and south India: a two centre population based study in people aged 60 years and over. PLoS One. 6(12):e28588.

Rumm-Kreuter, D., Demmel, I., 1990. Comparison of vitamin losses in vegetables due to various cooking methods. J. Nutri. Sci. Vitaminol. 36:S715.

Singh, R.R., Harshal, A., 2016. Effects of Cooking on Content of Vitamin $\mathrm{C}$ in Green Leafy Vegetables. Sch. J. Agric. Vet. Sci. 3(6):416-423.

Walingo, K.M., 2005. Role of vitamin C (ascorbic acid) on human health-a review. Afr. J. Food, Agri., Nutr. Develop. 5(1):1-12.

\section{How to cite this article:}

Mst. Rita Khatun, Mst. Khodeza Khatun, Md. Shadiqul Islam, Sharif Md. Al-Reza. 2019. Effect of Different Cooking Methods on Vitamin C Content of Some Selected Vegetables. Int.J.Curr.Microbiol.App.Sci. 8(10): 2658-2663. doi: https://doi.org/10.20546/ijcmas.2019.810.307 